\title{
Пространственная организация водных фитоценозов Бурлинской озерно-речной системы
}

\section{Spatial organization of water phytocenosis of the Burlinsky river-lake system}

\author{
Соколова М. И., Зарубина Е. Ю. \\ Sokolova M. I., Zarubina E. Yu. \\ Институтводных и экологических проблем СО РАН, г. Новосибирск.E-mail: smi1181@таil.ru, \\ Institute for Water and Environmental Problems SB RAN, Novosibirsk, Russia
}

\begin{abstract}
Peфepam. Исследована пространственная организация водных фитоценозов Бурлинской озерно-речной системы. Проанализированы таксономическая структура флоры и структура экологических форм по отношению к водному фактору. Более высокое флористическое разнообразие растительности отмечено в верховьях бассейна реки. Различия в видовом разнообразии растительности на разных участках бассейна объясняются различием спектров местообитаний (морфометрия, свойство грунтов, гидрологические факторы) и степенью антропогенной нагрузки.
\end{abstract}

Ключевые слова. Видовое разнообразие, макрофиты, река, тип зарастания, флора.

Summary. The spatial organization of water phytocenosis of the Burlinsky river-lake system was investigated. The taxonomical structure of flora and structure of ecological forms in relation to a water factor were analyzed. Higher floristic variety of vegetation is noted in head area of river basin. Differences in species variety between different areas of river basin can be explained by distinction of ranges of habitats (a morphometry, property of bottom sediments, hydrological factors and so on) and degree of anthropogenic impact.

Key words. Flora, macrophytes, overgrowing type, river, species diversity.

Высшие водные растения как составная часть водных биогеоценозов находятся в тесной взаимосвязи со средой обитания и факторами среды. Степень развития растительности, видовой и экобиоморфологический состав макрофитов и их распределение в водоеме обусловливается особенностями экологических условий и подчиняется определенным закономерностям.

Бассейн реки Бурлы с многочисленными озерами и замыкающим озером Большое Топольное - одна из бессточных озерно-речных систем, расположенных в междуречье Оби и Иртыша. Река приурочена к вытянутой с северо-востока на юго-запад ложбине древнего стока. Средний уклон реки $0,08 \%$ \%. Река начинается в подзоне южной лесостепи и последовательно пересекает несколько подзон степной зоны - умеренно-засушливо-степную, засушливо-степную и сухо-степную, т. е. верховье находится в районе с большим увлажнением, чем низовье (Золотов, Черных, 2014).

Водосбор реки Бурлы делится на три неравные части. На верхнем участке водосбора, в ленточном бору, река протекает через ряд небольших проточных озер (Прыганское, Верхнее, Нижнее и др.), кроме того, в ложбине древнего стока расположена цепь озер, соединяющихся между собой протоками. Сток из этих озер только во время паводков поступает в р. Бурлу (Б. Пустынное, Большое и др.). Озера имеют извилистую форму, вытянуты вдоль долины стока реки, как правило, окружены болотами или займищами с топкими, труднопроходимыми берегами. Русло реки здесь не имеет четкого положения среди озёрно-болотных ландшафтов.

В среднем течении ширина русла реки 20-40 м, течение спокойное, извилистые участки русла чередуются с относительно прямолинейными. Берега реки заросшие, устойчивые. Здесь на протяже- 
нии почти 180 км озер практически нет. Река проходит через заболоченные урочища и займища, покрытые растительностью и представляющие собой бывшие озера.

В нижнем течении реки большое количество проточных озер, на которых сток зарегулирован системой плотин. В разные по водности годы и периоды уровенный режим Нижне-Бурлинских озер сильно меняется, поэтому глубина, площадь, минерализация и степень зарастаемости в разные годы и сезоны значительно различаются. Большинство исследованных озер мелководные, с хорошо развитой литоралью. По минерализации и соотношению главных ионов, воды озер верхнего течения и некоторых озер нижнего течения (М. Топольное, Кабанье, Хомутиное) относятся к содовым, гидрокарбонатно-натриевым (кальциевым) I типа, в нижнем течении - к сульфатно-натриевым I-II типов, по классификации О. А. Алекина (1953). Активная реакция среды (рН) в момент исследования на всех озерах изменялась от слабощелочной (оз. Большое) до сильнощелочной (оз. Нижнее) (Кириллов и др., 2010).

Работа выполнена на основе натурных данных, полученных в ходе комплексных экспедиционных исследований в 2010-2011 гг. на р. Бурле (в ходе работы заложено 14 ключевых участков в верхнем, среднем и нижнем течении реки) и 12 озерах, в той или иной степени связанных с рекой: Большое Пустынное, Прыганское, Большое, Верхнее, Нижнее, Малое Топольное, Кабанье, Хомутинское, Песчаное, Хорошее, Кривое, Большое Топольное (рис. 1). Исследования проводили с применением стандартных методов сбора, гербаризации и описания высшей водной растительности (Руководство..., 1992). Всего сделано 72 полных геоботанических описания, собрано 245 листов гербарного материала. Для более полной характеристики видового разнообразия учтены литературные данные (Дурникин, 2010, 2013). Используемая в работе номенклатура таксонов по сосудистым растениям соответствует сводке (Черепанов, 1995). Экологические группы выделены по В. Г. Папченкову (2001) с учетом условий обитания на исследованной территории и объединением групп гелофиты и гигрогелофиты в группу гелофиты. При анализе флоры выделено «водное» и «околоводное» ядро. К «водному ядру» отнесены истинно-водные растения гидро- и гелофиты, весь жизненный цикл которых связан с водной средой. «Околоводное ядро» включает группу прибрежно-водных растений - гигро- и гигромезофитов. Тип зарастаемости озер выполнен на основе классификации А. Г. Поползина (1967). Типы зарастания рек выделены по схеме 3. В. Синкявичене (1992).

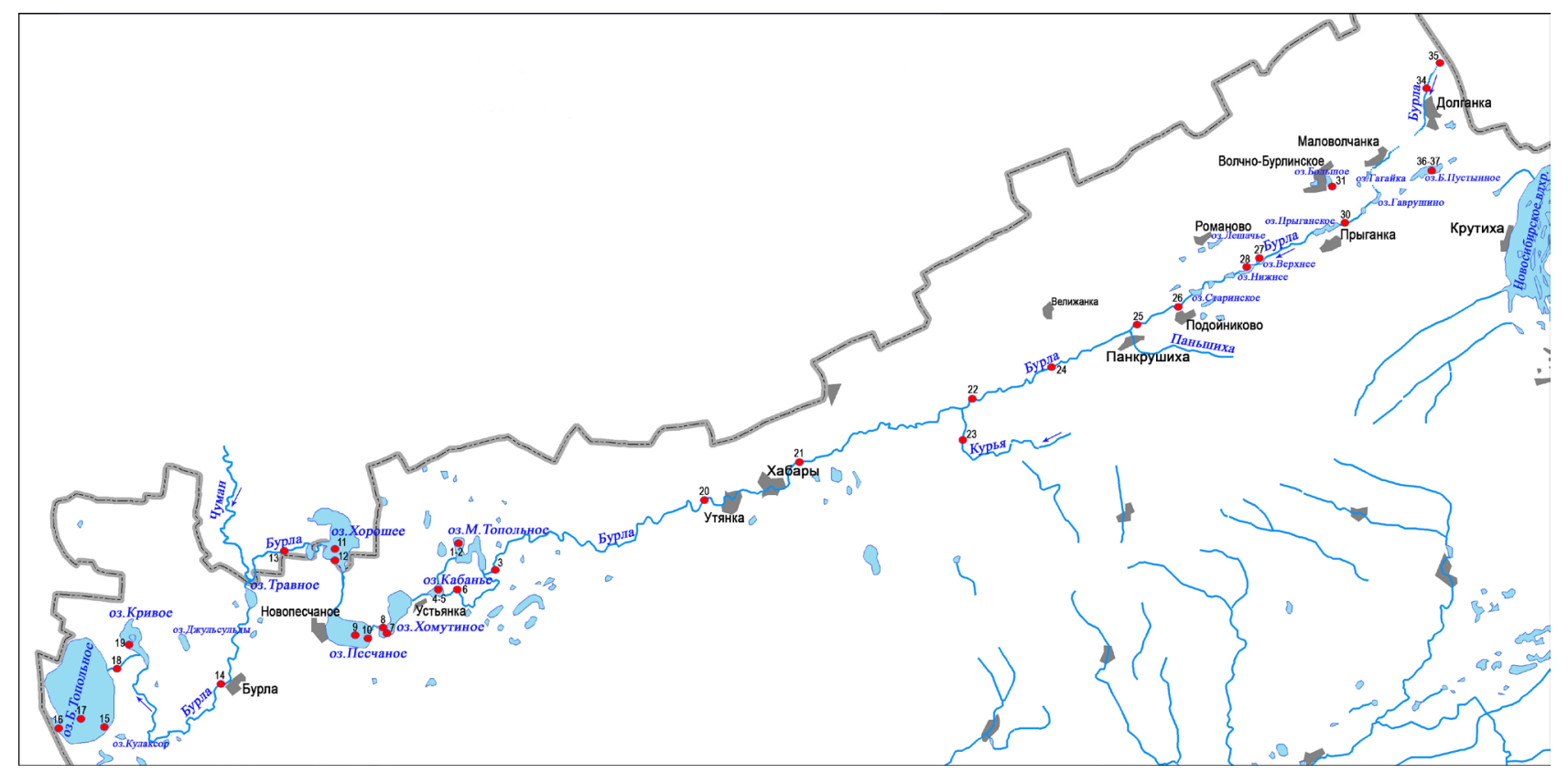

Рис. 1. Схема бассейна р. Бурла с указанием точек отбора проб.

Флора Бурлинской озерно-речной системы включает 101 вид водных и прибрежно-водных растений из 6 отделов, 34 семейств и 55 родов (Зарубина, Соколова, 2017). Низшие растения представлены харовыми (Chara sp.) и зелеными нитчатыми (Cladophora sp.) водорослями, высшие: мохообразными 
- 3 видами (Ricciocarpus natans (L.) Corda, Drepanocladus aduncus (Hedw.) Warnst. и Amblystegium riparium (Hedw.) Bruch et al.), хвощами (Equisetum fluviatile L.), папоротниками (Thelypteris palustris Schott) и цветковыми (94 вид). Наибольшим видовым разнообразием отличаются семейства Суреraceae - 19, Potamogetonaceae -12 , Ranunculaceae -8 , Polygonaceae -6 и Poaceae -5 . Эти 5 семейств включают около 50 \% всех видов водных растений, отмеченных во флоре.

Видовое разнообразие макрофитов верхнего, среднего и нижнего течения р. Бурлы значительно отличаются (табл.). Максимальное видовое разнообразие отмечено в верхнем течении - 77 видов, из них 61 видов - представители «водного ядра», наибольшее число видов отмечено в семействах Cyperaceae - Potamogetonaceae - Ranunculaceae. На среднем участке реки встречен 31 вид (27 водных), ведущие семейства - Cуреraceae - Lemnaceae - Polygonaceae. На нижнем участке - 66 видов (46 водных), ведущие семейства - Cуреraceae - Potamogetonaceae - Poaceae. Таким образом, на всем протяжении реки наибольшее видовое разнообразие имеют представители семейства Сурeraceae, спектр других ведущих семейств вниз по течению реки значительно трансформируется.

Таблица

Таксономическое и экологическое разнообразие различных участков

Бурлинской озерно-речной системы

\begin{tabular}{|c|c|c|c|}
\hline & Верхнее течение & Среднее течение & Нижнее течение \\
\hline Длина участков, км & 390-489 км & $228-390$ км & $0-228$ км \\
\hline $\begin{array}{l}\text { Количество исследован- } \\
\text { ных озер }\end{array}$ & 5 & 0 & 7 \\
\hline \multicolumn{4}{|c|}{ Таксономическое разнообразие } \\
\hline Число видов & 77 & 31 & 66 \\
\hline Число семейств & 46 & 26 & 46 \\
\hline Число отделов & 6 & 3 & 5 \\
\hline Доминирующие виды & $\begin{array}{l}\text { Озерные: Phragmites } \\
\text { australis, Typha angustifo- } \\
\text { lia, Ceratophyllum demer- } \\
\text { sum, Stratiotes aloides } \\
\text { Речные: Sparganium } \\
\text { erectum, Alisma planta- } \\
\text { go-aquatica }\end{array}$ & $\begin{array}{l}\text { Речные: Alopecurus } \\
\text { aequalis, Carex acuta, } \\
\text { Eleocharis palustris, Ve- } \\
\text { ronica anagallis-aquatica, } \\
\text { Ceratophyllum demersum, } \\
\text { Cladophora } \text { sp. }\end{array}$ & $\begin{array}{l}\text { Речные: Alopecurus aequa- } \\
\text { lis, Potamogeton macrocar- } \\
\text { pus, P. pusillus, Cladophora } \\
\text { sp. } \\
\text { Озерно-речные: Phrag- } \\
\text { mites australis, Potamoge- } \\
\text { ton pectinatus, Ceratophyl- } \\
\text { lum demersum }\end{array}$ \\
\hline \multicolumn{4}{|c|}{ Экологические группы (число видов) } \\
\hline Гидрофиты & 28 & 8 & 17 \\
\hline Гелофиты & 33 & 19 & 29 \\
\hline Гигро- и гигромезофиты & 16 & 4 & 20 \\
\hline
\end{tabular}

В верхнем течении преобладают озера с массивно-зарослевым типом зарастания, что характерно для низко минерализованных гипогалинных непроточных или малопроточных озер (Прыганское, Верхнее, Нижнее, Б. Пустынное). В таких озерах растительность занимает значительную часть акватории (от 70 до 95 \% площади озера). Широко распространены сообщества как погруженных и плавающих гидрофитов с доминированием Potamogeton pectinatus L., P. perfoliatus L., Ceratophyllum demersum L., Stratiotes aloides L., так полупогруженных гелофитов с доминированием Phragmites australis (Cav.) Trin. ex Steud., Typha angustifolia L. (Зарубина, Соколова, 2018). В верхнем течении так же встречаются озера со сплавинным типом зарастания. Такой тип отмечен в малых мелководных с заболоченными берегами олигогалинных озерах (Верхнее, Нижнее). Макрофиты занимают плавающие острова - сплавины, способные передвигаться по акватории озер. Доминируют Ceratophyllum demersum, Stratiotes aloides.

Русло реки в верхнем течении узкое, с глубинами 0,2-0,3 м, грунты приемущественно илисто-песчаные. Для этого участка реки характерен фрагментарный тип зарастания, здесь доминируют гелофиты (рис. 2), такие как Sparganium erectum L., Alisma plantago-aquatica L. Некоторые участки, 


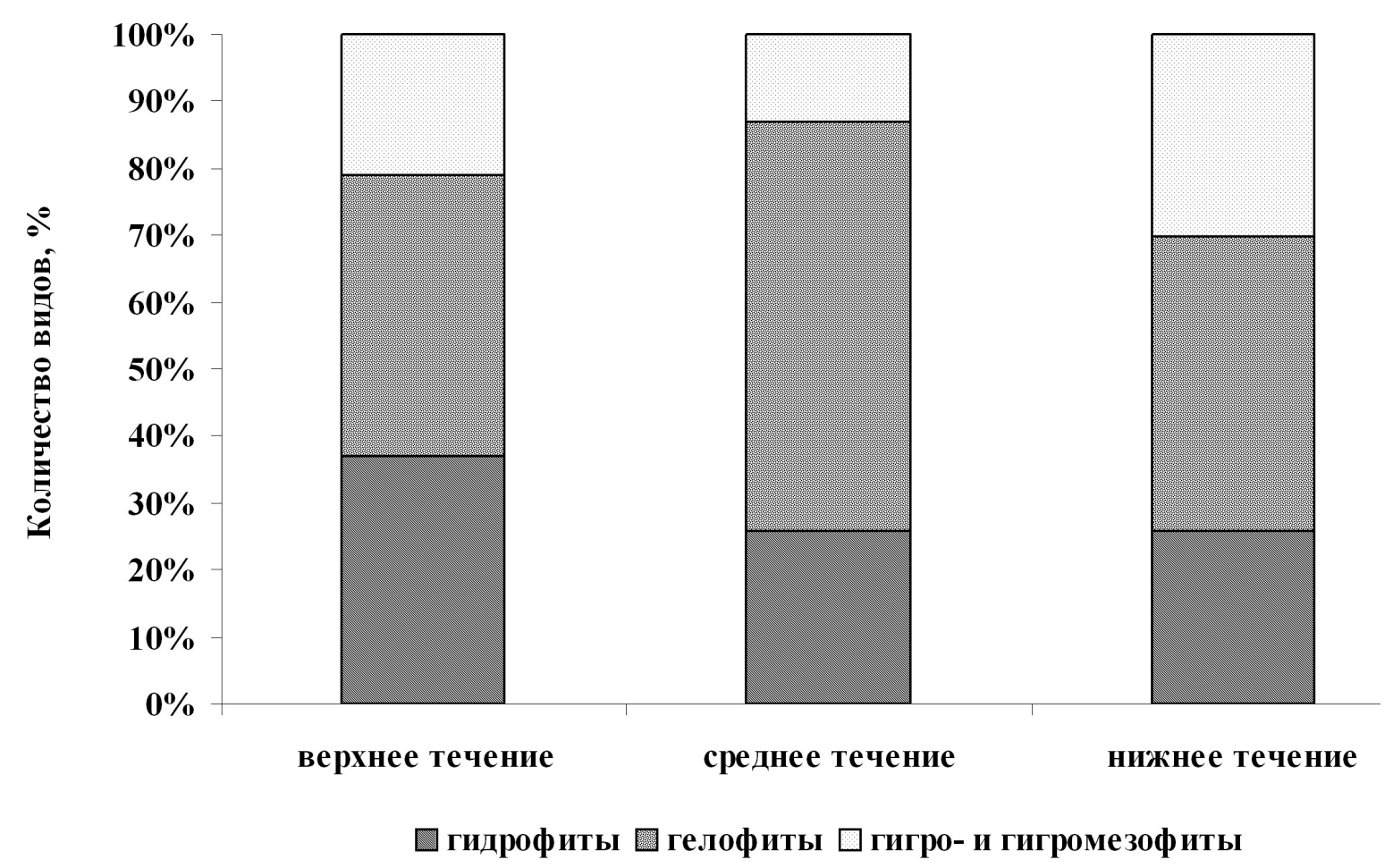

Рис. 2. Экологический спектр водной флоры Бурлинской озерно-речной системы.

где практически отсутствует течение, затянуты сплошным ковром гидрофитов (Spirodela polyrhiza (L.) Schleid. и Lemna minor L., L. trisulca L. и Stratiotes aloides). На таких участках реки тип зарастания сплошной. В целом для этого участка Бурлинской озерно-речной системы характерна высокая доля в экологическом спектре гидрофитов (42\%).

В среднем течении река проходит через заболоченные урочища и займища, покрытые растительностью и представляющие собой бывшие озера. Тип зарастания - прибрежно-фрагментарный. Основная роль в зарастании принадлежит гелофитам: Carex acuta L., Alopecurus aequalis Sobol., Eleocharis palustris (L.) Roem. et Schult., Alisma plantago-aquatica, Sparganium gramineum Georgi, Veronica anagallis-aquatica L.; на втором месте гидрофиты: Ceratophyllum demersum, Cladophora sp., Lemna trisulca. Довольно часто среди гигрофитов встречается Galium palustre L.

Для нижнего течения характерны озера с займищным и бордюрным типом зарастания. Займищный тип встречается в проточных озерах (М. Топольное, Хомутиное, Кабанье и др.). Суммарные площади зарастания в таких озерах составляют 40-65 \%. Однако при общем обилии растительности сохраняется четкая зональность в их распределении в глубину водоемов. Сообщества надводных растений окаймляют озеро почти со всех сторон и характеризуются мозаичностью, прерываясь небольшими плесами чистой воды и протоками. Ведущий вид, гелофит - Phragmites australis. Для пояса погруженных гидрофитов характерно доминирование рдестов: Potamogeton pectinatus и P. perfoliatus L., Chara sp., Ceratophyllum demersum. Бордюрный тип встречается в озерах Б. Топольное, Песчаное, Хорошее и др. и формируется из пояса тростника (Phragmites australis) в ассоциациях с рогозом узколистным (Typha angustifolia) и камышом озерным (Scirpus lacustris L.), а также рдестами Potamogeton pectinatus и P. perfoliatus. Заросли высшей водной растительности занимают не более 30 \% общей акватории водоема.

Нижнее течение реки подвержено антропогенной нагрузке, здесь чередуются фрагментарный и прибрежно-фрагментарный тип зарастания. Среди гидатофитов доминируют Potamogeton pectinatus, P. macrocarpus Dobroch., Cladophora sp. и Ceratophyllum demersum. Среди гелофитов - Alopecurus aequalis, Phragmites australis. Среди гигрофитов - Bolboschoenus maritimus (L.) Palla и Juncus compressus Jacg. 
Таким образом, в пространственной организации водных фитоценозов Бурлинской озерно-речной системы наблюдаются определенные закономерности. Наибольшее видовое разнообразие водной растительности и степень зарастания реки и связанных с ней озер отмечается в верхнем течении. Это связано с морфометрическими и гидрохимическими особенностями водоемов, а также более благоприятными климатическими факторами.

На видовой состав и структуру водных фитоценозов среднего течения большое влияние оказали гидрологические характеристики (отсутствие на этом участке озер, заболоченность или пересыхание в межень отдельных участков русла), что привело к низкому видовому разнообразию и преобладанию полупогруженной и околоводной растительности.

Ведущими факторами, влияющим на видовое разнообразие погруженной растительности в озерах нижнего течения, являются уровенный режим и минерализация воды, которые значительно меняются как в годовом, так и в сезонном аспектах. Колебание уровня воды приводит к изменению глубины, площади и минерализации, что влияет на степень зарастаемости водоемов, таксономическое разнообразие и структуру водных фитоценозов.

Работа выполнена по государственному заданию ИВЭП СО РАН в рамках Научной программы 134.1. «Исследование палео- и современных изменений состояния водоемов и водотоков Сибири, анализ природных и антропогенных изменений для стратегии охраны, использования и обеспечения безопасности водных ресурсов Сибири» при частичной финансовой поддержке гранта РФФИ № 17-0500404 .

\section{ЛИТЕРАТУРА}

Алекин О. А. Основы гидрохимии. - Л., 1953. - 296 с.

Дурникин Д. А. Глава 3. Макрофиты // Биоразнообразие Карасукско-Бурлинского региона (Западная Сибирь) / Отв. ред. Ю. С. Равкин. - Новосибирск: Изд-во СО РАН, 2010. - С. 72-79.

Дурникин, Д. А. Флора водоемов юга Обь-Иртышского междуречья: монография. - Барнаул: Изд-во АлтГУ, 2013. - $168 \mathrm{c}$.

Зарубина Е. Ю., Соколова М. И. Гигрофильная флора Бурлинской озерно-речной системы (Обь-Иртышское междуречье) // Проблемы ботаники Южной Сибири и Монголии : сб. науч. ст. по материалам XVI междунар. науч.-практ. конф. (Барнаул, 5-8 июня 2017 г.). - Барнаул: Изд-во АлтГУ, 2017. - С. 78-82.

Зарубина Е. Ю., Соколова М. И. Связь видового разнообразия макрофитов с морфометрией и гидрохимическими характеристиками озер (на примере разнотипных водоемов Бурлинской озерно-речной системы, юг Обь-Иртышского междуречья) // Проблемы ботаники Южной Сибири и Монголии: сб. науч. ст. по материалам XVII междунар. науч.-практ. конф. (Барнаул, 24-27 мая 2018 г.). - Барнаул: Изд-во АлтГУ, 2018. - С. 66-70.

Золотов Д. В., Черных Д. В. Репрезентативность модельного бассейна р. Касмалы для сравнительных ландшафтно-гидрологических исследований на Приобском плато // Изв. АлтГУ. Сер. биол. науки, науки о Земле, химия. 2014. № 3/1. - С. 133-138.

Кириллов В. В., Зарубина Е. Ю., Котовщиков А. В., Кириллова Т. В., Долматова Л. А., Ермолаева Н.И., Соколова М. И. Состав и структура водных экосистем бассейна реки Бурлы в 2010 году. // Наука - Алтайскому краю 2010 г.: Сб. статей. - Барнаул: Алтайский дом печати, 2010. - Вып. 4. - С. 239-252.

Папченков В. Г. Растительный покров водоемов и водотоков Среднего Поволжья. - Ярославль: ЦМП МУБи HT, 2001. $-200 \mathrm{c}$.

Поползин А. Г. Озера Обь-Иртышского бассейна (Зональная комплексная характеристика). - Новосибирск: Зап.-Сиб. кн. изд-во, 1967. - 350 с.

Руководство по гидробиологическому мониторингу поверхностных экосистем / Под ред. В. А. Абакумова. СПб.: Гидрометеоиздат, 1992. - 318 с.

Синкявичене 3. В. Характеристика растительности средних и малых рек Литвы:. Автореф. дис. ...канд. биол. наук. - Вильнюс, 1992. - 28 с.

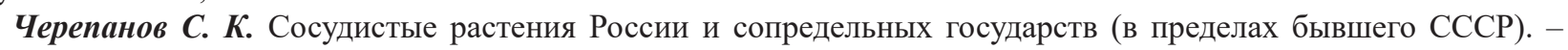
СПб.: Мир и семья, 1995. - 992 с. 